INFORMAL LOGIC

XI.1, Winter 1989

\title{
Just the Facts Ma'am: Informal Logic, Gender and Pedagogy
}

\section{DEBORAH ORR York University}

From the time of Aristotle's Organon through most of the present century, the study of logic has meant the study of formal logic. Only recently, mainly within the last two or three decades of this century, has this been questioned and challenged by the rapidly growing and influential development of informal logic. Blair and Johnson have identified two major streams which have fed "the informal logic movement". ${ }^{1}$ These were the discontent of instructors in introductory logic courses with formal logic as an efficacious tool for teaching reasoning and argumentation and the theoretical insight that formal deductive logic is not commensurate with argumentation in natural language. The meeting of these two streams has proved fruitful: At least two new journals, Informal Logic and Argumentation, devoted to the study of informal logic, conferences devoted to it, and a large and rapidly growing body of journal articles, monographs and textbooks. ${ }^{2}$ The impression I have received over the past decade or so, the time during which I have been following this movement somewhat and using its insights and developments in my own classrooms, has been that informal logic has been received as a breath of fresh air by teachers and students alike, a way of teaching reasoning and argumentation skills that is fresh, exciting and useful. But my own early, and may I say uncritical, enthusiasm for informal logic has abated over the past several years. What first appeared to be a large, if largely unexplored, box of tools for human reasoning now seems a somewhat more limited set of instruments. In this paper I would like to discuss the clues that have led me to believe the toolbox is less than fully equipped and to make some suggestions as to where informal logic might look to enlarge its stock of implements.

There have been three broad types of things which have led to my current discontent with the theory and practice of informal logic. First of all was the nagging but inchoate sense that the sorts of things I was thinking about and the ways in which I thought about them, as an individual, a student and then as a researcher, were, somehow, wrong. For instance, I have long had an interest in ethics but found that there was little if anything in classical statements of theory that bore a relationship to what I did as a moral thinker. Art and literature, I discovered as a student, could illuminate my practice but philosophy and logic largely did not. This sense of being on the wrong track dogged most of my academic career. I dealt with it by learning as quickly and thoroughly as possible the appropriate ways of proceeding in academe-the alternative was failure and personal embarrassment. But the price I paid for this success was the sense that while I was clever to get as good as I did at what was expected of me, on some deep level I was inadequate, that what I was doing did not come 'naturally' to me. The price of success was a continual battle against myself and my deepest inclinations.

In addition to my personal experience as a thinker was my experience as a teacher. During my career I have taught a "critical skills' course for several years and have also been involved in a fairly wide range of entry level university courses in the humanities and social sciences which have stressed the development of reasoning and writing skills. 
Among these have been several courses and subgroups within courses comprised entirely of English as a Second Language (ESL) students. While I have not carried out systematic research, I have developed the same strong impressions which I find are shared by many teaching at this level: Our students lack what we consider to be elementary skills in reading, writing and thinking. They cannot interpret their assignments. They fail to understand the main points or discern the supporting arguments in the material they read. And so forth. While there is a general recognition that ESL students employ different rhetorical styles from Canadian-born English-speaking students, this is largely seen as something to be corrected. My response to all this has been fairly typical: I gripe a lot with my colleagues and try to develop strategies to correct my students' faulty practices, e.g., develop exercises to teach them how to analyze a text or send them off to the Essay Tutoring Centre to learn how to develop and use a thesis statement. In sum, I have seen my students as people with problems which I ought to try to remedy.

Lastly, my research interests in epistemology and women's studies have gradually led me to think that my style of rationality, and in many instances that of my students, is not wrong but rather simply different from the dominant style. However, our differences have not been recognized as such, have not been accorded respect and certainly not been fostered in educational institutions, and more broadly in a culture, dominated by what I have come to see as a too narrow and often inappropriate conception of rationality.

In the rest of this paper I will survey some of the empirical and theoretical support for the contention that this culture's conception of rationality, especially as it is reflected in our educational institutions and the materials and practices we as teachers use, is far too narrow. Particularly I will argue that it is time for the informal logic movement, because of the growing influence it exerts through informal logic texts, introductory logic courses and critical skills courses, to recognize, theoretically ground and incorporate into its texts alternative styles of rationality. My focus will be, in fact, on only one of what I believe is a range of alternative styles. I call this the feminine style, in contrast with the dominant or masculine style because, while it has been empirically linked with women in contemporary North America, it is theoretically grounded in the psychology of femininity as gender. I will not speak to the question of the styles of rationality which a study of such variables as race, class or ethnicity might uncover. ${ }^{3}$

Reasoning has been seen as a masculine activity at least since the time of Aristotle. As Genevieve Lloyd has shown through her incisive historical examination of western philosophy, "Rationality has been conceived as transcendence of the feminine" 4 and the feminine in turn has been defined in opposition to and exclusion of the masculine. The feminine is 'the other' to the masculine 'self' and has been seen as primitive and underdeveloped. Thus she argues that Augustine's conceit that mind has no sex must be abandoned. This culture's conceptions of mind and rationality are overwhelmingly male.

A strong contingent within the feminist movement, at least from Wollstonecraft and Mill onward, has argued that the difference between male and female performance in reasoning lay not in inherent capacity but in socialization. Give women the proper education, they believed, and they would prove themselves fully the intellectual equals of men. Since their time many women have proved that they could use the masculine mode of reasoning as successfully as men. But it was the work of Carol Gilligan $^{5}$ which provided some of the earliest and most important empirical evidence for the nature of the difference between men's and women's reasoning as well as a theoretical account of that difference 
in the psychology of gender.

Stimulated by Kohlberg's research into moral development but skeptical of his generalization of his findings to all of humanity since his initial research was conducted on male subjects only, Gilligan focused in her work on the moral reasoning of girls and women. Her research has uncovered two distinct modes of thinking about moral dilemmas which she calls the ethic of care and the ethic of justice. Although they are not sex-linked, the ethic of care is empirically associated with women and the ethic of justice with men. ${ }^{6}$ Each utilizes a different fundamental assumption: "While an ethic of justice proceeds from the premise of equality - that everyone should be treated the same-and ethic of care rests on the premise of nonviolence-that no one should be hurt', ${ }^{7}$ But the most striking differences between the two emerge when we examine the style of reasoning each employs. The ethic of justice is consonant with the style reported by Kohlberg, ${ }^{8}$ the dominant masculine style, in that it proceeds deductively and at its highest stage of development embraces a universal moral principle such as Kant's categorical imperative or the Golden Rule. It values 'objectivity' and thus will not be influenced by the agent's relationships, concerns for specific others or the particulars of the case. It aims for universal justice. In contrast to the formality and abstraction characteristic of the ethic of justice, the ethic of care employs a style which is 'contextual and narrative'. Relationships, responsibilities and the concrete particulars of the case are definitive of the moral dilemma for this ethic; they can not be filtered out. It seeks solutions which ensure that none are hurt, which "alleviate the 'real and recognizable trouble' of this world", 9 rather than ones which are universalizable.

In Gilligan's analysis, "the logic underlying an ethic of care is a psychological logic of relationships, which contrasts with the formal logic of fairness that informs the justice approach." 10 These logics in turn are formed by the differential experience of gender formation undergone by male and female children in this culture. Female children, because they are raised by women who see them as like themselves, are encouraged to develop a self-identity centering on attachment and relationship while male children are perceived by their mothers as different from themselves and are encouraged to separate and develop a sense of self as isolated and autonomous. In Nancy Chodorow's words, "Girls emerge from this period with a basis for 'empathy' built into their primary definition of self in a way that boys do not." 11 Thus gender theory provides a causal account of two contrasting conceptions of rationality which are instantiated in the ethical styles Gilligan delineates in her work. The two rationalities can be seen as distinct with regard to both 'content', what is thought about, and 'form', how it is thought about.

Similar findings of genderized thought patterns linked to sex have been reported by others including Lyons who has further tested and substantiated Gilligan's findings. ${ }^{12}$ Pigott, who views what I call the feminine mode as an impediment to be overcome, reports that not only do entry level university students exhibit this difference but that at a recent meeting which she attended, discussion of topics of concern to women, whether led by academic or nonacademic women, "soon bogged down in 'confessions' from the women in the audience of one personal experience after another' . ${ }^{13}$ Based on a sample of one thousand writing placement tests, half taken by men and half taken by women, she finds a significant difference in topics chosen and in "male-female thinking patterns". ${ }^{14}$ When given the same choices of topics, "The majority of men preferred to write about the politics of the school system; the majority of women preferred to write about themselves and their parents." 15 Men avoid the personal; women prefer it. Male thought patterns were analyzed as deductive, female as inductive, although I would argue that 
this analysis is a function of Pigott's a priori acceptance of those categories of logic and that the examples she reproduces of women's papers could well be read as exhibiting Gilligan's 'narrative' mode rather than falling into the traditional category of induction. Her logical commitments can be deduced from her overall assessment of women students, that they "limit, even thwart, their intellectual development by employing exclusively intuitive analysis. They rely solely on personal experience in their thinking, in their focusing on topics, and, most notably, in their writing, scribbling a world of particulars within which the incident is isolated, individual, nongeneralizable, and stunted because it does not relate to universal concepts which could give it meaning." 16

Although he uses the terms 'female mode' and 'male mode' ${ }^{17}$ where I have used 'feminine mode' and 'masculine mode' to denote the influence of gender, Thomas Farrell more carefully analyzes and differently categorizes the style of thinking which Pigott has stigmatized as so dysfunctional. Farrell holds that the 'female mode', which he calls the mode of indirection, is distinct from inductive reasoning,

although in a sense it certainly proceeds inductively. The conventional textbook distinction between inductive and deductive organization, it seems to me, is simply a distinction between two forms of the male mode which proceed by differentiation and antithesis. Both present the product of thought in a carefully controlled way, although the ordering or arrangement of ideas is different. The "indirection" of the female mode, on the other hand, tries to simulate how one might actually reason to a conclusion, and differentiation and antithesis are not especially accentuated. Deductive and inductive organization denote arrangements of discourse that appear to be planned in advance, whereas the "indirection" of the female mode seems to proceed without a readily recognizable plan. The thinking represented in the female mode seems eidetic, methectic, open-ended, and generative, whereas the thinking in the male mode appears framed, contained, more preselected, and packaged. The ideas seem less processed and controlled in the female mode than in the male mode and hence come closer to recreating the process of thinking as it normally occurs in real life ... The female mode seems at times to obfuscate the boundary between the self of the author and the subject of the discourse, as well as between the self and the audience, whereas the male mode tends to accentuate such boundaries. The emphasis on explicitness (even when understatement is used for ironic effect) in the male mode seems to support a need for closure, whereas the "indirection" and implicitness in the female mode seem to offer an openness that could be useful in reconciling differences. ${ }^{18}$

Farrell also notes that the male mode tends to employ the structural device of beginning with a thesis and ending with a conclusion, thus allowing for more "playfulness" in the development or body of the work because the listener or reader is clear about where the discourse is headed.

His last two sentences in the above quotation indicate that these two styles meet the psychological demands of the gender of their practitioners which I have sketched above. Farrell cites a number of studies, including some work of his own, which show that the indirect mode is to be found in the writing of historical and contemporary women and which go some way to relating the modes employed by men and women to the type of education they had received. ${ }^{19}$

Farrell illuminates the nature of the hegemony of the 'male mode' in western culture when he notes that Peter Ramus, author of influential medieval textbooks on reasoning, censures those who deviate from what he regards as the " one and only method', that is, reasoning from general principles baldly stated to particulars", ${ }^{20}$ i.e., the 'male mode'. Clearly Ramus is teaching a narrow version of what Moulton $^{21}$ has called The Adversary Method to the disparagement and exclusion of the feminine mode of reasoning. While Moulton offers many criticisms of the underlying assumptions of The Adversary 
Method and its claims to historical precedent, a major drawback which she points to which is relevant to my concerns is that it "accepts only the kind of reasoning whose goal is to convince an opponent, and ignores reasoning that might be used in other circumstances: To figure something out for oneself, to discuss something with likeminded thinkers, to convince the indifferent or the uncommitted.' 22 Thus its use to the exclusion of other modes fosters not only bad but potentially divisive reasoning. (The adversarial mind-set of informal logic texts today is reflected even in the titles of some of them, e.g., How to Win an Argument, Logical Self-Defense.) In contrast Farrell finds that the 'female mode' avoids antagonism, stresses solidarity with its audience and is "generally supportive, conciliatory, and potentially integrative" ${ }^{23}$

It is not my intention in this paper to fully defend the feminine mode but rather to make a contribution to describing and understanding it to the end that it be recognized and taught as a part of what humans do when they reason. I fully subscribe to Wittgenstein's dictum that, if we do not want our conception of logic to be based on superstition and illusion, then we must "look and see", and accept, what people actually do when they think. ${ }^{24}$ I will, however, offer a comment on one point and that is the oft expressed fear that modes of thinking which incorporate the affective and relational aspects of the thinker's life, ones that give the subjective dimension an equal place beside, or even primacy over, the objective are bound to be both unreliable and selfserving. As Lloyd and Moulton, among many others, have argued, the masculine mode has been developed with the explicit intent of excluding the emotional and subjective. It will take much argumentation about many interrelated issues to overcome this view and for now I will offer only as an illustrative counter example the methodology of the widely acclaimed geneticist and Nobel Laureate, Barbara McClintock.

McClintock is described by Evelyn Fox
Keller as a methodological rebel. Eschewing the 'objective' method of normal science, McClintock employed an epistemological stance and rational style which are closely akin to that of the feminine mode of reasoning I have been discussing. She argued that modern research methods are vitiated by a tendency to impose preconceived answers (the hypothesis or thesis) and to ignore or force fit information which did not cohere with one's preconceptions. Feeding this are assumptions about the world (that its organization can best be understood by dichotomizing divisions, e.g. subject-object, mind-matter, feeling-reason) and the goal of science (to produce unifying laws) which McClintock also rejected. For McClintock the goal of science was to make the differences she saw understandable and this necessitated a kind of respect, even love for and union with her material that ordinary science does not recognize, in fact forbids.

In comparing the 'epistemology of division' of ordinary science with McClintock's 'epistemology of difference', Keller has said, "Division severs connection and imposes distance; the recognition of difference provides a starting point for relatedness. It serves both as a clue to new modes of connectedness in nature, and as an invitation to engagement with nature.', 25 A methodology of relatedness and connection, of feeling and intuition, enabled McClintock to ask question of nature, to think about it and make discoveries which were all outside the range of ordinary science. But, Keller argues, McClintock's method of empathy with her material, her 'feel for the organism', was not solipsistic: It led to the production of knowledge which is reliable, that can be shared with and reproduced by the scientific community. ${ }^{26}$

This last claim is supported by McClintock's argument that she was not doing 'feminist' science but claiming science as a fully human endeavour. She believed that she was employing human capabilities and she trusted that, contrary to the position 
taken by centuries of western thinking, the 'subjective' was not unruly and erratic but a reliable and trustworthy source of knowledge. This meant that in her work, while she had been socialized to, and to some degree employed the methodology of, ordinary science, she was able to mitigate that distorted practice with the techniques of her distinctive empathic approach to the world. She believed that as a person and as a scientist she must struggle to transcend gender and Keller reads her work as evidence of her success. In this she is both compatible with the theoretical possibilities of Chodorow's theory of gender which I brought to bear in my discussion above, and in line with a body of evidence which finds that both men and women can and do employ both styles of rationality.

Fundamental to Chodorow's theory is the idea that gender results from the polarization and asymmetrical development of a shared human potential. The psychological process of gender acquisition produces girls who have, as we have seen, 'a basis for 'empathy' built into their primary definition of self in a way that boys do not" 27 and boys with a psychic structure centered on what Chodorow calls a " pseudo-independence." 28 These are the sorts of differences which ground the different styles of rationality uncovered by Gilligan's work. But, to repeat, these difference are not inherent but acquired. Chodorow locates their social roots in the sexed divisions of labour within and among the family, home and workplace in contemporary capitalist society. The clear implication of this is that the transcendence of gender and all that hangs on it, on more than an haphazard and infrequent basis, requires changes in those spheres. But this topic is beyond the scope of my paper.

Besides Keller's discussion of Barbara McClintock's work, Farrell provides other examples of women who successfully use both rational styles. For instance his analysis of Virginia Woolf's $A$ Room of One's $O w n$ shows Woolf quite conscious- ly using both styles and manipulating them to create a work which combines exposition, fiction and argumentation in a unique and satisfying way. ${ }^{29} \mathrm{But}$ the incorporation of the feminine mode is not unique to highly successful and visible women like McClintock and Woolf as is shown by the in-depth study conducted by Mary Belenky and her colleagues $^{30}$ of the epistemic styles and development of 135 women drawn from a variety of backgrounds ranging from elite colleges to social agencies. They discovered five distinct epistemic positions which were expressed in the different 'voices' of the women they studied: (1) silence-is the lack of a voice of women who have been abused and abandoned and consequently see external authorities as all powerful; (2) received knowledge and (3) procedural knowledge-are the voices of women who try to 'fit in' and accept society's definitions of reason and objectivity; (4) subjective knowledge-is the voice of women who are on a 'quest for self' and in this process reject public definitions of truth and authority for ones which are private and subjectively known; and (5) constructed knowledge-is the most mature voice of women and results from

\begin{abstract}
an effort to reclaim the self by attempting to integrate knowledge that they felt intuitively was personally important with knowledge they had learned from others. They told of weaving together the strands of rational and emotive thought and of integrating objective and subjective knowing. Rather than extricating the self in the acquisition of knowledge, these women used themselves in rising to a new way of thinking. ${ }^{31}$
\end{abstract}

An important feature of the thinking of women at this position was that they 'abandoned either/or thinking', the epistemic stance of division, for that of difference. ${ }^{32}$ Further, Like McClintock, they questioned and recast their paradigms and methodologies alike. Belenky et al. report that for their subjects, "Question posing and problem posing become prominent methods 
of inquiry...[they] tend not to rely as readily or as exclusively on hypothetico-deductive inquiry, which posits an answer (the hypothesis) prior to the data collection, as they do on examining basic assumptions and the conditions in which a problem is cast." 33 Thus these women were able to utilize and integrate the techniques of both rational modes to become "passionate knowers", ones for whom "connected knowing is not simply an 'objective' procedure but a way of weaving their passions and intellectual life into some recognizable whole". ${ }^{34}$ Clearly, for these women rationality is not partitioned off from the rest of their selves and lives but integrates and serves these.

Finally, Carol Gilligan has found that mature men as well as mature women can and do 'weave together' both modes. Although they might have been initially committed to one ethic or the other, Gilligan found that crises in personal relationships or professional life can lead both sexes to critically examine and expand their decision making procedures toward a "convergence" 35 of the two.

Though both sexes move away from absolutes in this time, the absolutes themselves differ for each. In women's development, the absolute of care, defined initially as not hurting others, becomes complicated through a recognition of the need for personal integrity. This recognition gives rise to the claim for equality embodied in the concept of rights, which changes the understanding of relationships and transforms the definition of care. For men, the absolutes of truth and fairness, defined by the concepts of equality and reciprocity, are called into question by experiences that demonstrate the existence of differences between other and self. Then the awareness of multiple truths leads to a relativizing of equality in the direction of equity and gives rise to an ethic of generosity and care. For both sexes the existence of two contexts for moral decision makes judgment by definition contextually relative and leads to a new understanding of responsibility and choice. ${ }^{36}$
Gilligan does not find that harmonizing these two voices, these two deeply different styles of rationality, is an easy task for her subjects. One, in grappling with a dilemma in her professional life which challenged the adequacy of her ethic of care by itself, found it necessary to adopt a principle of rights which left her with "two principles of judgment whose integration she cannot yet clearly envision". ${ }^{37}$ Nevertheless, Gilligan believes that the dialogue between the two voices can lead to a fuller understanding and transformation of many of the areas of human life and relationship which are so problematic for us today.

Since its inception as a science, logic has conceived of itself as the study of the eternal and universal laws of thought. While they believed that its study might serve as a corrective to faulty practices, thus giving logic a practical role in education, logicians have not seen themselves as recommending one set of procedures from among a collection of valid alternatives but rather as describing the a priori 'one right way to think'. Informal logic's recent arrival on the scene has challenged the received belief that formal logic adequately describes how people proceed when they reason in ordinary language. As Blair and Johnson point out, the subject matter of informal logic is "communicative practice" and some of its major theoreticians hold that, "arguments as products of communication in such natural language practices as rational persuasion or rational inquiry are simply not chains of deductive inferences." 38 I believe that in this the informal logic movement has made a genuine and liberating advance but, as the large and growing body of studies of the feminine mode of rationality show, it is time for informal logic to take the next step, to expand its understanding of what rationality and argumentation are when they are understood as human, not masculine, practice. To dismiss the feminine mode of rationality with the stock charge of 'mere psychologism' would be at best question begging, at worst prejudice. 
I have drawn on research from a variety of different sources to show first that the feminine mode or style of rationality is, in fact, practiced and can be found quite readily in environments as different as elite colleges and social agencies, in fields as disparate as genetic research and moral practice. While researchers have not used a standardized vocabulary to describe and analyze the feminine mode, to compare it with the masculine or to study the integration of the two, the similarities in their accounts cannot be missed: the very epistemic foundations of the feminine and masculine modes of rationality are different. Within broad areas of thought and inquiry they begin with different assumptions and strive for different goals. In contrast to the masculine mode, the feminine mode does not fit comfortably into the standard categories of induction or deduction. Gilligan has called its form 'narrative', utilizing the 'psychological logic of relationships', and Farrell, 'indirect'. Chodorow and Keller have used the term 'empathic' to mark the blurring of boundaries between thinker and subject of inquiry and Belenky notes the integration of subject and object in her practioners of constructive knowledge. Relationship with and concern and respect for the other are central to this method. The affective and relational are integral and can not be suspended, as is attempted in the demand for objectivity of the masculine mode. While the masculine mode proceeds by differentiation and antithesis with the goal of one of a pair of opposites emerging as dominant, the feminine mode preserves differences. The masculine mode has been described as controlled, packaged and having closed boundaries while the feminine is open-ended and more closely simulates actual thought processes. Writing in the masculine mode more frequently begins with a thesis and ends with a conclusion than writing in the feminine and Farrell maintains that the feminine mode places more trust in its audience to draw conclusions. Perhaps we might rephrase this by saying that the feminine mode requires a more active involvement on the part of its audience. Finally, the masculine mode has been characterized as adversarial and potentially divisive while the feminine is conciliatory, integrative and stresses solidarity.

Clearly, these descriptions are preliminary to the fuller study and description of the feminine mode, and its integration with the masculine, as processes of 'rational persuasion and inquiry'. For informal logic this will mean, among other things, a study of the role and use of the 'subjective' in the feminine mode, the study and description of typical patterns of inquiry and persuasion and the identification and study of 'fallacies' typical of this mode. And similiar concerns must be brought to bear in a study of the integrated use of the two modes.

Two consequences of the thesis that both the feminine and the masculine modes are rooted in gender need to be stressed. First, it follows that since gender is an acquisition and not sex determined, both modes of rationality are potentially open to both sexes. Second, both theoretical and empirical research support the hypothesis that early influences on an individual's development as well as whether or not she or he receive support and direction in later years influence the individual's access to the various modes of rationality. On the theoretical level Chodorow's work, especially in showing gender acquisition as the polarization of human potential, ground this claim. On an empirical level Gilligan has found that despair and moral nihilism, rather than development toward maturity and the convergence of the moral voices, characterized those women who have felt themselves abandoned and unsupported in their decision making during a time of crisis. ${ }^{39}$ And in far greater detail the work of Belenky and her colleagues show how the environment and life experiences of their subjects have helped or hindered their development through the different forms of knowledge. ${ }^{40}$ All too frequently these 
women's experiences in educational institutions have not fostered but suppressed constructed knowing. They have paralleled the experience of the philosopher Sara Ruddick who has written,

Harvard's training, and the identity it allowed, had become intimately, unconsciously connected with lessons of respectability I had learned as a child .... Even now, I can surprise myself, wondering whether a question is "really" philosophical, whether I should ask questions I haven't been trained to answer. ${ }^{41}$

The lesson in this for those involved in informal logic, be they developing theory, writing texts or teaching, is that for the full range of human thinking to develop we must collectively recognize the validity of modes of thinking other than the dominant masculine strain and actively foster their development. Among other things this calls for the understanding of thinkers as other than disembodied minds. They are rather persons with useful affective and empathic tools to bring to intellectual life. It is to these tools and their uses and limits which informal logic must now turn its attention.

\section{Notes}

1 Blair, J. Anthony and Ralph H. Johnson, "The Current State of Informal Logic" Informal Logic, IX 2\&3. Spring \& Fall, 1987, pp. 147-152.

2 I have relied on two useful bibliographies: Johnson, Ralph H. and Blair, J. Anthony, "A Bibliography of Recent Work in Informal Logic", prepared for the Symposium on Informal Logic, University of Windsor, June 26, 1978 and "Informal Logic Texts: An Annotated Bibliography," Prepared by Jean Saindon, York University, July, 1988. The former lists journal articles, monographs and textbooks while the later focuses on texts.

3 Harding, Sandra, "Is Gender a Variable in Conceptions of Rationality: A Survey of Issues", Beyond Domination, ed. by Carol C. Gould, Rowman \& Allanheld, New Jersey, 1983 , pp. $44-62$, fn. 5 gives a guide to some of the recent literature on European vs. nonEuropean modes of rationality.

4 Lloyd, Genevieve, The Man of Reason: "Male" and "Female" in Western Philosophy, Univ. of Minnesota Press, Minneapolis, 1984, p. 104.

5 Gilligan, Carol, In a Different Voice, Harvard Univ. Press, Cambridge, Mass., 1982.

6 Ibid., p. 2.

7 Ibid., p. 174

8 See especially Kohlberg, Lawrence, "The Development of Children's Orientations Toward a Moral Order: 1. Sequence in the
Development of Moral Thought', Vita Humana, 6, 1963, 11-33 and Kohlberg, Lawrence, "The Cognitive Developmental Approach to Moral Education', Phi Delta Kappan, June 1975, 670-677.

9 Gilligan, op. cit., p. 100

10 Ibid., p. 173.

11 Chodorow, Nancy, The Reproduction of Mothering, Univ, of California Press, Berkeley, 1978, p. 167 quoted in Gilligan, op. cit., p. 8.

12 Lyons, Nona Plessner, "Two Perspectives: On Self, Relationships and Morality", Harvard Educational Review, 53, No. 2, May 1983, pp. 125-145.

13 Pigott, Margaret B., "Sexist Roadblocks in Inventing, Focusing, and Writing", College English, 40, April 1979, p. 922.

14 Ibid., p. 927.

15 Ibid., p. 923.

16 Ibid., p. 922, emphasis in the original.

17 Farrell, Thomas J., "The Female and Male Modes of Rhetoric', College English, 40, April 1979 , pp. 909-921. Farrell's position that these modes are rooted in biology (fn. 14) does not affect his description and categorization of them which are my main concerns. Obviously, I reject this thesis.

18 Ibid., pp. 909-910. 
19 Ibid., p. 911, especially the studies by Allison Heisch and Patricia A. Sullivan.

20 Ibid., p. 911.

21 Moulton, Janice, "A Paradigm of Philosophy: The Adversary Method"' in Discovering Reality, ed. by Sandra Harding and Merrill B. Hintikka, D. Reidel Pub. Co., Dordrecht Holland, 1983, pp. 149-164.

22 Ibid., p. 199

23 Farrell, op. cit., pp. 916-917.

24 Wittgenstein, Ludwig, Philosophical Investigations, trans. by G.E.M. Anscombe, Basil Blackwell, Oxford, 1968, see especially section 66.

25 Keller, Evelyn Fox, "A World of Difference", in Reflections on Gender and Science, Yale Univ. Press, New Haven, 1985, p. 163.

26 Ibid., p. 166.

27 Chodorow, op. cit., p. 167.

28 Ibid., p. 187.

29 Farrell, op. cit., pp. 913-916.

30 Belenky, Mary Field, Blythe McVicker Clinchy, Nancy Rule Goldberger and Jill Mattuck
Tarule, Women's Ways of Knowing, Basic Books, Inc., New York, 1986.

31 Ibid., pp. 134-135.

32 Ibid., p. 137.

33 Ibid., p. 139.

34 Ibid., p. 141.

35 Gilligan, op. cit., p. 2.

36 Ibid., p. 166.

37 Ibid., p. 165.

38 Blair and Johnson, "The Current State of Informal Logic" p. 147.

39 Gilligan, op. cit., especially Chap. 4, passim.

40 Belenky et al., op. cit., passim.

41 Ruddick, Sara, "A Work of One's Own' in Working It Out, ed. by S. Ruddick \& P. Daniels, Pantheon, New York, 1977, p. 137, quoted in Belenky et al., op. cit., p. 96.

DEBORAH ORR

3 DOUVILLE COURT

TORONTO, ONTARIO

M5A 4E7

\section{\$Philosophy}

Teaching Philosophy is a quarterly journal which serves as a forum for the exchange of ideas and information about the teaching and learning of philosophy. Articles, discussions, reports and reviews are published on topics such as:

- theoretical issues in the teaching of philosophy

- innovative methods and classroom stratagems

- experimental and interdisciplinary courses

- faculty development and student counseling

1990 Subscriptions: $\$ 19.50$ individuals; $\$ 48$ institutions. Add $\$ 4$ for all subscriptions outside the U.S. Order from the PHILOSOPHY DOCUMENTATION CENTER, Bowling Green State University, Bowling Green, OH 43403-0189 USA.

Edited by: Arnold Wilson, University of Cincinnati, Cincinnati, $\mathrm{OH}$ 45221-0206. 